\title{
Two cases of insulin autoimmune syndrome induced by exogenous insulin in diabetic patients
}

\author{
Yuanyuan Fan ${ }^{1}$, Xian $\mathrm{Jin}^{2}$, Jinping Zhang*2 \\ ${ }^{1}$ Department of Endocrinology, Inner Mongolia Steel Hospital, Baotou, Inner Mongolia, China \\ ${ }^{2}$ Department of Endocrinology, China-Japan Friendship Hospital, Beijing, China
}

Received: September 29, 2017

DOI: $10.14725 /$ dcc.v4n4p17
Accepted: November 1, $2017 \quad$ Online Published: December 10, 2017

URL: http://dx.doi.org/10.14725/dcc.v4n4p17

\begin{abstract}
Objective: To improve the recognition of clinicians on insulin autoimmune syndrome (IAS) induced by exogenous insulin. Methods: Two cases of IAS induced by exogenous insulin were retrospectively analyzed.

Results: Two patients had hypoglycemia occurred during the night. They had dissociation between C-peptide and insulin, accompanied by high titer of insulin autoantibody (IAA). Hypoglycemia episodes were ameliorated after the use of oral hypoglycemic agents.

Conclusions: Due to the role of insulin to be covered up, diabetes patients after the application of exogenous insulin induced IAS are easily misdiagnosed, high titer IAA and insulin and C-peptide separation phenomenon have been confirmed with diagnostic value.
\end{abstract}

Key Words: Exogenous insulin, Insulin autoimmune syndrome, Insulin autoimmune antibody

Insulin autoimmune syndrome (IAS) is an important cause of hypoglycemia, firstly proposed by Hirata, ${ }^{[1]}$ also known as Hiarta disease. The classic IAS diagnosis is based on spontaneous hypoglycemic episodes in the absence of exogenous insulin, high levels of serum immunologically active insulin and high titers of insulin autoimmune antibody (IAA). ${ }^{[2]}$ The use of exogenous insulin can also lead to IAS. In 1960, Harwood ${ }^{[3]}$ firstly reported type 1 diabetic patients with long-term use of insulin. Insulin was stopped for 23 days due to persistent severe hypoglycemia. A high titer of insulin antibody complex was detected in vivo. At present, cases of exogenous human insulin leading to IAS are still rare. Since the first report in 2005 in China, more than 20 cases of similar cases have been reported. The 2 cases reported in this study aimed at raising awareness of these diseases.

\section{Clinical data}

\subsection{Case 1}

A 62-year-old male patient visited the Department of Endocrinology, Beijing China-Japan Friendship Hospital in February 2016. The patient has no obvious causes of dry mouth, polyuria and polydipsia 4 months ago, and the blood plasma blood glucose $(11.0 \mathrm{mmol} / \mathrm{L})$ in the empty stomach was tested in the external hospital. After 2 hours of steamed bread, plasma glucose of $15.0 \mathrm{mmol} / \mathrm{L}$ was detected, which was diagnosed as type 2 diabetes. Mixed Protamine Zinc Recombinant Human Insulin Injection 26 U/d was used for hypoglycemic treatment. After 1 months of insulin injection, the symptoms of palpitation and sweating appeared from 0 a.m. to 3 a.m. in the morning, and

\footnotetext{
*Correspondence: Jinping Zhang; E-mail: ppzhang74@163.com; Address: Department of Endocrinology, China-Japan Friendship Hospital, Beijing, China.
}

Published by New Century Science Press 
the lowest blood sugar was $3.0 \mathrm{mmol} / \mathrm{L}$ at the time of attack. Symptoms could be relieved after eating. Because of repeated hypoglycemia after 2 months, Protamine Zinc Recombinant Human Insulin Injection combined oral medication was used to control blood glucose, but there was still nocturnal hypoglycemia. After that, Protamine Zinc Recombinant Human Insulin Injection was changed to Insulin Glargine Injection, but the hypoglycemia was not relieved, and itchy spots and subcutaneous fat atrophy gradually appeared, so the patient visited the Endocrinology Clinic of China-Japanese Friendship Hospital. Insulin was discontinued, and metformin $(1,500 \mathrm{mg} / \mathrm{d})$ and sitagliptin phosphate $(100 \mathrm{mg} / \mathrm{d})$ were used to lower glucose. The routine examination of hematuria, liver and kidney function, thyroid function and abdominal color Doppler were all normal. The history of the use of sulfhydryl drugs was denied, and the history of malignant tumor or the symptoms of tumor consumption were denied as well. Half a month after the withdrawal of insulin, IAA $>100 \mathrm{U} / \mathrm{ml}$ (normal value $<10 \mathrm{U} / \mathrm{ml}$ ), anti-insulin antibody, glutamic acid decarboxylase antibody negative; HbA1c $6.4 \%$. The result of steamed bread meal: blood glucose values were 7.19 $\mathrm{mmol} / \mathrm{L}, 14.67 \mathrm{mmol} / \mathrm{L}, 15.57 \mathrm{mmol} / \mathrm{L}$ respectively under empty stomach, 1 hour later and 2 hour later; insulin levels were $122.4 \mu \mathrm{IU} / \mathrm{ml}, 291.5 \mu \mathrm{IU} / \mathrm{ml}, 442.6 \mu \mathrm{IU} / \mathrm{ml}$, serum C-peptide values were $2.4 \mathrm{ng} / \mathrm{ml}, 5.82 \mathrm{ng} / \mathrm{ml}, 8.92 \mathrm{ng} / \mathrm{ml}$ (insulin and C-peptide determination by electrochemiluminescence, normal fasting insulin 2.6-24.9 $\mu \mathrm{IU} / \mathrm{ml}$, normal C peptide $1.1-4.4 \mathrm{ng} / \mathrm{ml}$ ). IAA was $60.62 \mathrm{U} / \mathrm{ml}$ after 2 months of insulin deactivation. After 6 months of follow-up, the patient had no hypoglycemia, and blood glucose was monitored to be $6 \mathrm{mmol} / \mathrm{L}$ or so. Usually 2 hours after meals, blood glucose fluctuated in 6-10 $\mathrm{mmol} / \mathrm{L}$.

\subsection{Case 2}

An 83-year-old male patient was admitted at Department of Endocrinology, Beijing China-Japan Friendship Hospital, in May 2015. 32 years ago, the patient was diagnosed as "type 2 diabetes", and had metformin, glibenclamide hypoglycemic for treatment. During the hospitalization in the Department of Orthopedics in January 2016, Recombinant Human Insulin Injection $32 \mathrm{U} / \mathrm{d}$ and Protamine Zinc Recombinant Human Insulin Injection $6 \mathrm{U} / \mathrm{d}$ were used to reduce sugar treatment. The injection site gradually appeared red induration. After 4 months of insulin injection, the patient had symptoms such as hunger, palpitation, sweating and so on, which could be relieved after eating. The blood glucose was not monitored for further treatment in the Department of Endocrinology of China-Japan Friendship Hospital. Past medical history included hypertension for 30 years. Olmesartan medoxomil $20 \mathrm{mg} / \mathrm{d}$ was orally taken. The history of the use of sulfhydryl drugs was denied. Liver, kidney and thyroid function were tested to be normal. The abdominal ultrasound examination result was normal as well. IAA > 100U/ml, anti insulin cell antibody and glutamic decarboxylase antibody were negative, and glycosylated hemoglobin was $8.0 \%$. The result of steamed bread meal: blood glucose values were $5.58 \mathrm{mmol} / \mathrm{L}, 14.08$ $\mathrm{mmol} / \mathrm{L}, 19.81 \mathrm{mmol} / \mathrm{L}$ respectively under empty stomach, 1 hour later and 2 hour later; insulin levels were 791.4 $\mathrm{IU} / \mathrm{ml},>1,000 \mathrm{IU} / \mathrm{ml}$ and > 1,000 IU/ml, C-peptide levels were $1.81 \mathrm{ng} / \mathrm{ml}, 5.31 \mathrm{ng} / \mathrm{ml}$ and $6.73 \mathrm{ng} / \mathrm{ml} \mathrm{respec}-$ tively. The levels of insulin and C-peptide were determined by electrochemiluminescence. Normal fasting insulin was 2.6-24.9 IU/ml, normal C-peptide 1.1-4.4 ng/ml. Nateglinide $180 \mathrm{mg} / \mathrm{d}$ and acarbose $300 \mathrm{mg} / \mathrm{d}$ treatment were used when the insulin therapy was stopped. After 2 months of follow-up, the patient had no symptoms of hunger, palpitation and sweating. Fasting blood glucose was monitored to fluctuate in 5.9-8.7 mmol/L. 2 hours after regular meals, blood glucose fluctuated in 6.7-15.4 mmol/L.

\section{Discussion}

\subsection{Clinical manifestations and features}

In recent years, the prevalence of diabetes increases year by year, insulin treatment is an important means of controlling hyperglycemia, but after the use of exogenous insulin or insulin analogues, local allergic reactions, insulin resistance, hypoglycemia symptoms and other problems caused by insulin injection appear as well. However, there is no unified standard for the diagnosis of IAS induced by exogenous insulin. This disease may be considered in patients with the following clinical manifestations: ${ }^{[4]}$ (1) Repeated nocturnal and postprandial hypoglycemia after the use of exogenous insulin for a period of time in diabetic patients. (2) The concentration of immunoreactive insulin in blood is significantly higher than that of C-peptide, which is isolated from insulin and C peptide. (3) IAA positive. (4) Other causes of hypoglycemia. The above two cases were diagnosed as diabetes. There were frequent hypoglycemic reactions after the application of insulin. The liver and kidney function of the patient was normal, and there was no adrenocortical dysfunction, no history and manifestation of malignant tumor. The thyroid function was in the normal range, no occupation of pancreas, and the level of insulin was significantly increased. The C-peptide was normal or slightly elevated, and was isolated from the markedly elevated insulin level, and IAA was positive. Therefore, the hypoglycemic reaction was considered to be IAS induced by insulin.

Although the primary structure of human insulin is the same as endogenous insulin, it still has a certain immunogenicity, which induces the production of insulin antibodies. Compared with the animal-derived insulin preparations, the antigenicity of the exogenous human insulin and the incidence of local reaction at the injection site were significantly decreased. ${ }^{[5]}$ Studies have found that the IAA positive rates 
of patients with type 1 diabetes caused by animal insulin and human insulin were $29 \%$ and $14 \% .{ }^{[6]}$ Insulin antibodies in serum can bind to free insulin in large quantities, leading to an increase in the total immunologically active insulin content in serum. In that case, very high insulin levels can be detected that do not match the blood sugar. While the proinsulin structure contains C-peptide, the measured immunoreactive C-peptide reflects the level of free Cpeptide and proinsulin bound to autoantibodies. The value of serum C-peptide can rise up to 100 times as high as that of normal people. However, due to the fact that the proportion of proinsulin in the blood is not high, the level of C-peptide is much lower than the high concentration of insulin in blood. It shows separation state of C-peptide and insulin. ${ }^{[7]}$ In this study, blood insulin levels were significantly increased in both patients, up to greater than 1,000 $\mu \mathrm{IU} / \mathrm{ml}$, showing a low C-peptide level compared with high levels of insulin, suggesting a mismatch between C-peptide and synchronized insulin levels. The symptoms of hyperglycemia appear when insulin combines with the antibody cannot play hypoglycemic effect. Hyperglycemia stimulates islet B cells to release more insulin, and then binds to the antibody, resulting in the accumulation of insulin. The insulin bound with the antibody suddenly dissociates from the antibody under a certain inducement, which leads to hypoglycemia. ${ }^{[8]}$ Ping F et al. ${ }^{[9]}$ summarized 17 cases of autoimmune insulinemia induced by insulin. The average interval between the use of insulin and repeated hypoglycemia was 32 (5-96) months. The average lowest blood glucose level was 2.2 (1-3.3) $\mathrm{mmol} / \mathrm{L}$, which was accompanied by disturbance of consciousness or convulsion. The alternative phenomenon of hypoglycemia and hyperglycemia appeared in 12 patients (that is, the fluctuation of blood sugar over the same day was over $11.0 \mathrm{mmol} / \mathrm{L}$ ). In this study, the patient in case 1 had an interval of 1 month between insulin and repeated hypoglycemic reactions, and 4 months in case 2 , which was shorter than that reported by Ping F et al., ${ }^{[9]}$ suggesting that insulin-induced autoimmune hypoglycemia time variability is relatively large.

\section{References}

[1] Hirata Y. Insulin autoimmune syndrome. Nihon Rinsho. 1973; 31(7): 2227-2231. PMid: 4795320.

[2] Uchigata Y, Eguchi Y, Takayama-Hasumi S, et al. Iusulin autoimmune syndrome (Hirata disease): clinical features and epidemiology in Japan. Diabetes Res Clin Pract. 1994; 22(2-3): 89-94. https : //doi .org/10.1016/0168-8227 (94)90040-X

[3] Harwood R. Insulin-binding antibodies and "spontaneous" hypoglycemia. N Engl J Med. 1960; 262(12): 978-979. PMid: 14400231 https ://doi.org/10.1056/NEJM196005122621908

[4] Zhao XF, Zhuang XM, LI R, et al. 3 cases of autoimmune hypoglycemia induced by exogenous insulin and literature review. J Capit

\subsection{Treatments}

Treatment methods are as follows: (1) Stopping the use of induced drugs: the symptoms of about half of the patients with hypoglycemic episodes are gradually relieved after changing the insulin form or stopping the use of insulin instead of oral hypoglycemic drugs. Oral acarbose can increase the absorption of carbohydrates, avoid further endogenous insulin production stimulation, thereby reducing the peak to valley effect. Other oral insulin secretagogues and metformin can also be used to control blood sugar, but more attention needs to be paid in hypoglycemia when using secretagogues. In this study, the patient in case 1 was treated with metformin and sitagliptin phosphate, the patient in case 2 was switched to nateglinide and acarbose. Hypoglycemia was basically relieved after treatment. (2) The use of corticosteroids: glucocorticoids can quickly and effectively alleviate hypoglycemia, but the pros and cons of the use of glucocorticoid remain to be evaluated. Glucocorticoid can be used for intractable hypoglycemia in patients with elder age and high cardiovascular risk. A moderate dose of prednisone $(30-40 \mathrm{mg} / \mathrm{d})$ is usually used for 2-4 weeks after treatment, and patients have negetive antibodies in 5-6 months. It is necessary to take specific measures if blood sugar rises after the use of hormones. (3) Plasma replacement therapy, immunosuppressive agents cannot be used as major treatments as their effects are uncertain.

We often focus on the insulin hypoglycemic effect itself when dealing with repeated hypoglycemia or blood glucose fluctuation in diabetic patients after injection of insulin. It is often considered that the dose or dosage form of insulin is not used properly so that IAS is often missed after insulin injection. If IAA is detected in patients who do not respond well by simply increasing or decreasing insulin doses, and if C-peptide, glucose and insulin are examined simultaneously, more IAS may be found. The patient should be more appropriately treated instead of simply adjusting the dose of insulin.

\section{Conflicts of Interest Disclosure}

The authors have no conflicts of interest related to this article.

Med Univ. 2014; 35(4): 521-525.

[5] Fineberg SE, Kawabata TT, Finco-Kent D, et al. Immunological responses to exogenous insulin. Endocr Rev. 2007; 28(6): 625-652. PMid: 17785428. https://doi.org/10.1210/er.2007-0002

[6] Schernthaner G, Borkenstein M, Fink M, et al. Immunogenicity of human insulin (Novo) or pork monocomponent insulin in HLADRtyped insulin-dependent diabetic individuals. Diabetes Care. 1983; 6(Suppl 1): 43-48. PMid: 6343038.

[7] Pu S, Yang WY. Autoimmune hypoglycemia. Chinese Journal of Diabetes Mellitus. 2007; 15(1): 60-61.

[8] Yang XJ, Bian RW, Gu LB, et al. A case of autoimmune hypoglycemia caused by exogenous human insulin. Chin J Intern Med. 2008; 47(11): 954-955. 
[9] Ping F, Zhang HB, Wang LJ, et al. A summary of cases of autoimmune hypoglycemia induced by exogenous insulin and review of literature. Chinese Journal of Diabetes Mellitus. 2013; 5(6): $347-$ 350 .

[10] Shuai Y, Pu S, Xing XY, et al. Three cases of autoimmune hypoglycemia caused by exogenous human insulin. Chinese Journal of Diabetes Mellitus. 2013; 5(4): 249-251.

[11] Tong XL. The strategy of TCM Research on diabetic vascular complications. Chinese Journal for Clinicians. 2013; 41(10): 1-3.

[12] Zhang TL, Zhang CX. Erbesartan combined with amlodipine besylate in the treatment of senile diabetes with hypertension and hyper- uricemia. Chinese Journal for Clinicians. 2011; 39(12): 25-27.

[13] Xiu SL, Wang L. Effect of pioglitazone on intervention and C reactive protein in prediabetic patients. Chinese Journal of Medicine. 2015; 50(1): 65-67.

[14] Dong YR, Wang L, Lin SS, et al. Comparison of the clinical characteristics of adult occult autoimmune diabetes with typical type 1 and type 2 diabetes. Chinese Journal of Medicine. 2014; 49(1): 57-59.

[15] Han LY. Observation of lipoic acid combined with epalrestat insulin aspart 30 in the treatment of type 2 diabetes peripheral neuropathy. China Medicine. 2012; 7(2): 163-165. 